\title{
Students misconceptions on chemical equilibrium and their consequences to biochemistry learning
}

\author{
Montagna, E. ${ }^{1}$; Marson, G. A. ${ }^{2}$; Torres, B.B. ${ }^{1}$ \\ ${ }^{1}$ Departamento de Bioquímica, IQ, USP, SP, Brazil \\ ${ }^{2}$ Departamento de Química Fundamental, IQ, USP, SP, Brazil
}

It is well documented that misconceptions on chemical equilibrium (CE) are widespread among students in higher education. Nevertheless CE concept is critical for biochemistry topics development such as buffer solutions, enzyme kinetics, allosteric enzymes, metabolic networks, among others. In the present work we performed tests in order to diagnose how students use the concepts of CE acquired in other courses. We tested high school and undergraduate students from two courses in two institutions, in four moments of their course: $a$. freshmen; b. after basic general chemistry courses; c. along the biochemistry course and $\mathrm{d}$. after physical chemistry courses. The tests dealt with: 1. tasks containing current terms, keywords and concepts about CE; 2 . tests that exclusively use symbolic representations of CE and 3. application of elementary concepts of CE in biochemistry. The results show that among the students: 1. more than $95 \%$ correctly answer questions of group $1 ; 2$. more than $50 \%$ fail in questions of group 2, and; 3. more than $50 \%$ fail in questions of the group 3 . We conclude that students solve tests on CE without really understand the concepts involved; consequently students are unable to work CE concepts without mathematical tools or conventional formulas. Finally, the results show that students are restricted to use CE concept only in the context in which it was learned and this certainly impairs the significant learning of the forthcoming biochemical contents.

Keywords: chemical equilibrium, misconceptions, interdisciplinary

Supported by: FAPESP 
This document was created with Win2PDF available at http://www.win2pdf.com. The unregistered version of Win2PDF is for evaluation or non-commercial use only. This page will not be added after purchasing Win2PDF. 